\title{
ПРОФИЛАКТИЧЕСКАЯ МЕДИЦИНА
}

\author{
УДК 613.262:63:616-006-08
}

\section{Овощи и плоды в профилактике и лечении рака в свете доказательной медицины (часть 2)}

\author{
В. В.Закревский, В. Г. Лифляндский \\ Северо-Западный государственный медицинский университет им. И. И. Мечникова, Российская \\ Федерация, 191015, Санкт-Петербург, ул. Кирочная, 41
}

Для цитирования: Закревский В. В., Лифляндский В.Г. Овощи и плоды в профилактике и лечении рака в свете доказательной медицины (ч. 2) // Вестник Санкт-Петербургского университета. Медицина. 2018. Т. 13. Вып. 1. С.91-105. https://doi.org/10.21638/11701/spbu11.2018.109

Методом литературного исследования проанализировано влияние овощей и плодов на риск развития рака предстательной железы, легких, поджелудочной железы, полости рта, глотки и гортани, пищевода и желудка, печени и желчного пузыря, почек и мочевого пузыря. Обоснована возможность их использования в профилактике этих заболеваний и повышении качества жизни больных раком. Установлено, что для снижения риска онкологических заболеваний важным является не столько использование отдельных групп фруктов и овощей, оказавших наиболее выраженное профилактическое действие на отдельные типы рака, сколько общая противораковая направленность всего рациона питания, а также достаточное потребление фруктов и овощей. Рекомендуемые уровни потребления овощей колеблются, по данным разных авторов, от 240 до 402 г в день, фруктов - от 160 до 460 г в день, пищевых волокон — от 25 г в день. Существенным недостатком является отсутствие норм для отдельных групп фруктов, ягод и овощей. Учитывая различные причины возникновения и разные механизмы развития отдельных форм и локализаций злокачественных опухолей, необходимо максимально дифференцированно подходить к оценке отдельных продуктов, локализаций рака, их разновидностей внутри каждой локализации, в том числе учитывать гистологический тип опухолей, а также генетические различия. Кроме того, важно проведение исследований с качественным дизайном на больших контингентах с исключением систематических и случайных ошибок, а также с учетом в первую очередь клинически значимых исходов (смертность и продолжительность жизни здоровых, качество жизни, скорость метастазирования, ангиогенеза и пролиферации опухоли у больных и т. п.), а не только благоприятной динамики лабораторных показателей.

Ключевые слова: овощи, фрукты, ягоды, профилактика и лечение рака, доказательная медицина.

(c) Санкт-Петербургский государственный университет, 2018 


\section{Введение}

Среди причин смерти на планете онкологические заболевания стоят на втором месте. Их профилактика, в особенности алиментарная, издавна привлекает к себе внимание ученых. Однако до сих пор информация о влиянии овощей и плодов на риск возникновения и развития рака различных органов довольно противоречива - от полного отрицания их полезности в профилактике рака до признания чуть ли не панацеей.

Целью исследования стали анализ данных о влиянии овощей и плодов на риск развития различных типов онкологических заболеваний и обоснование возможности их использования в профилактике рака и повышении качества жизни больных раком.

В работе использован метод литературного исследования по материалам современных отечественных и зарубежных публикаций.

\section{Результаты и обсуждение}

По данным экспертов Всемирного фонда исследования рака (ВФИР) 2007 года, пища, богатая ликопином и селеном достоверно с большой долей вероятности снижала риск рака предстательной железы (РПЖ) [1], но к 2014 году, по мнению экспертов фонда [2], значимость этих компонентов существенно снизилась до недостаточно научно обоснованной. В эту же группу вошли некрахмалистые овощи, овощи и фрукты, богатые пищевыми волокнами (ПВ), альфа-каротином, фолатом, витаминами С и Е, и БАДы с альфа-токоферолом. Аргентинские [3] и французские [4] исследователи также не обнаружили связи между потреблением овощей, фруктов и ликопина (томатных продуктов) с риском развития РПЖ.

Английские и итальянские исследователи [5] тоже пришли к выводу о «скромном» действии ликопина томатов на риск развития РПЖ. Вместе с тем они приводят данные о благоприятном влиянии ликопина (4 мг дважды в день) на больных РПЖ после резекции простаты и предлагают его в качестве дополнительного химиопрофилактического средства, нетоксичного и хорошо переносимого организмом. Авторы отмечают также тенденцию к снижению риска возникновения РПЖ при увеличении в питании крестоцветных овощей (все виды капусты), а также профилактику РПЖ и замедление его прогрессирования у больных при использовании гранатового сока. Они не рекомендуют использовать БАДы с селеном и витаминами Е и А для профилактики РПЖ до более точного выяснения вопроса об их влиянии.

Бельгийские урологи [6] отмечают, что, несмотря на обнадеживающие результаты в профилактике РПЖ с помощью различных пищевых веществ (ресвератрол, ликопин), имеются и негативные результаты использования некоторых из них, в частности кальция, селена и альфа-токоферола; поэтому авторы также призывают к осторожности применения БАДов, содержащих несколько биологически активных компонентов.

Американские ученые указывают на то, что селен не влиял на риск РПЖ, а альфа-токоферол на $17 \%$ повышал риск этого вида рака [7]; избыток омега-3 жирных кислот также повышал риск развития РПЖ. Гамма-токоферол, по данным иссле- 
дований [8], в отличие от альфа-токоферола, может снижать риск развития РПЖ. Одновременно указывается на отсутствие благоприятного влияния на риск РПЖ таких антиоксидантов, как селен, витамин С и бета-каротин. Относительно ликопина приводятся результаты различных исследований, свидетельствующие как об отсутствии эффекта, так и о снижении риска развития РПЖ на $16 \%(p=0,003)$ или на $38 \%$. Большинство каротиноидов (альфа-каротин, лютеин) также достоверно уменьшали риск РПЖ, в то время как бета-криптоксантин повышал его.

В совместном исследовании ученых США и Европы было установлено, что влияние ликопина на риск развития РПЖ зависит от наличия гена экспрессии белка ERG [9]. Так, у мужчин ERG-положительных ликопин оказывает защитное действие, снижая риск РПЖ на $30 \%(p=0,002)$, в то время как в группе ERGотрицательных отсутствует изменение риска РПЖ при употреблении таких же количеств ликопина (две и более порций томатопродуктов в неделю) ${ }^{1}$. Авторы указывают на необходимость учета генетических различий при изучении влияния нутриентов на риск развития РПЖ.

Ученые из США и Европы [10] при анализе 15 крупномасштабных исследований установили, что ретинол способствовал повышению риска общей заболеваемости РПЖ, в то время как альфа-токоферол снижал его. Одновременно они показали достоверную обратную связь ликопина и альфа-токоферола с риском развития только агрессивной формы РПЖ. Гамма-токоферол, по данным их анализа, никак не влиял на риск развития РПЖ.

Следует отметить существенное (на $42 \%$ ) снижение риска в основном низкодифференцированного РПЖ у мужчин, длительно употреблявших БАДы из экстракта виноградных косточек, по сравнению с теми, кто их не употребляли [11]. Риск развития высокодифференцированных опухолей при этом тоже снижался, но гораздо меньше - всего на $18 \%$. Виноградное вино, также богатое указанными соединениями, не влияло на риск возникновения РПЖ.

Специальное исследование по оценке влияния питания на риск развития особо агрессивных форм РПЖ позволило выявить достоверное снижение риска в группах с высоким потреблением овощей, богатых каротиноидами $(p=0,04)$, и листовых овощей $(p=0,02)$ по сравнению с группами минимального их потребления [12]. Однако в группе мужчин, потреблявших много продуктов питания, в том числе фруктов и овощей, с высоким гликемическим индексом риск развития агрессивного РПЖ достоверно повышался.

Норвежскими учеными было установлено, что только у веганов (изучались также группы на невегетарианском, лакто-ово-вегетарианском, песко-вегетарианском питании) заболеваемость РПЖ была достоверно на $35 \%$ ниже, чем у невегетарианцев [13]. Авторы отмечают, что веганы также употребляли меньше алкоголя, чем невегетарианцы и среди них гораздо меньше курящих.

Получены данные [14] о том, что потребление 8 унций (227 г) гранатового сока в день замедляет удвоение простатического специфического антигена (ПСА) до 54 месяцев в сравнении с 15 месяцами у испытуемых контрольной группы, не получавших сок. Это, по мнению исследователей, может не только замедлить прогрес-

11 порция томатопродуктов равна 1 помидору; 1 небольшому стакану томатного сока; 0,5 чашки (118,294 мл) томатного соуса или 2 пластинкам пиццы. 
сирование РПЖ, увеличить продолжительность жизни больных, но и улучшить качество их жизни.

Что касается использования отдельных нутриентов у больных, прооперированных по поводу РПЖ, то авторы из Англии [15] после метаанализа большого числа исследований установили, что ни один из изучавшихся нутриентов (ликопин, экстракт семян граната, селен, коэнзим Q и др.) не оказывал существенного влияния на клинически значимые исходы (скорость метастазирования, продолжительность жизни и пр.). Они отметили лишь благоприятную динамику лабораторных показателей, таких как ПСА, инсулиноподобный фактор роста - 1 и др. Авторы делают вывод о необходимости проведения более длительных и более тщательно организованных рандомизированных контролируемых исследований с учетом влияния изучаемых нутриентов в первую очередь на клинически значимые исходы и качество жизни больных РПЖ.

Эксперты ВФИР в 2007 году [1] на основании анализа большого числа наблюдений свидетельствовали о том, что фрукты оказывают убедительное защитное действие против рака легких (РЛ). Вместе с тем для питания, богатого каротиноидами, отмечено вероятное влияние, а для некрахмалистых овощей и питания, богатого кверцетином, лишь предполагаемое влияние на снижение риска развития РЛ. Следует особо отметить, что если употребление БАДов с витамином А (ретинолом) лишь предположительно увеличивало риск развития РЛ у курильщиков, то БАДы с бета-каротином (20 мг в день и более) делали это с высокой достоверностью и убедительностью.

В последующих работах также доказана обратная связь между потреблением овощей и фруктов и риском заболеваемости РЛ [16-18]. При этом наиболее выраженное защитное действие овощей и фруктов от РЛ установлено у курильщиков [17].

Что касается отдельных групп овощей и нутриентов, то среди населения Уругвая [16] наиболее выраженное защитное влияние на риск развития аденокарциномы легких оказывало питание с преобладанием крахмалистых овощей (картофеля, батата и тыквы) - $p<0,007$, а также зеленых овощей и разнообразных фруктов $p<0,01$. В группах китайцев с максимальным потреблением зеленых листовых овощей, овощей, богатых бета-каротином, и арбузов риск развития РЛ был соответственно на 28, 31 и $35 \%$ ниже, чем в группах с минимальным их потреблением [18]. Причем очень высокая достоверная обратная связь риска развития РЛ была выявлена китайскими учеными с потреблением витамина А и каротиноидов (не БАД) изучаемых групп продуктов $-p=0,01$ и $p=0,008$ соответственно, а наиболее выраженным оказалось влияние каротиноидов именно зеленых листовых овощей $(p=0,0001)$.

Особо следует отметить противораковое влияние рационального (здорового) питания, отличающегося в том числе высоким содержанием большинства овощей и фруктов [16; 19]. При этом достаточно одного только высокого потребления мяса на фоне низкого уровня фруктов и овощей в питании для достоверного увеличения риска развития карциномы легких [20].

В отношении рака поджелудочной железы продукты, содержащие фолат, из разряда вероятных, и фрукты из разряда предполагаемых в плане снижения его риска в 2007 году [1] переведены экспертами Всемирного фонда исследования рака 
в разряд недостаточно научно обоснованных в 2012 году [21]. В последнем разряде оказался и рацион, богатый витамином С.

Вместе с тем продукты и напитки, содержащие фруктозу (как натуральные, так и обогащенные ею), отнесены к предполагаемым в плане повышения риска рака поджелудочной железы. Так, каждые 25 г фруктозы увеличивали риск возникновения рака на $22 \%$ [21]. В качестве возможных механизмов такого негативного влияния фруктозы приводятся следующие: 1) постпрандиальное повышение уровня глюкозы, являющееся одним из факторов риска этого вида рака; 2) усиление окислительного стресса; 3) легкость (без инсулина) и быстрота метаболизации раковыми клетками фруктозы по сравнению с глюкозой (данный фактор способствует ускорению их пролиферации).

Большой группой исследователей из разных стран [22] в рамках ЕРІС была доказана U-образная связь между содержанием фолата в плазме крови и заболеваемостью раком поджелудочной железы - высокий риск при содержании фолата менее 5 ммоль/л постепенно снижался при увеличении концентрации фолата до 15-20 ммоль/л, а затем снова повышался при содержании фолата более 20 ммоль/л.

Увеличение потребления альфа-токоферола снижало риск развития рака поджелудочной железы при наблюдении за 29133 финскими курильщиками в проспективном когортном исследовании, проводившемся в течение 16 лет [23].

Достоверное снижение риска рака поджелудочной железы $(p=0,026)$ отмечалось исследователями из Миннесоты при употреблении 23 и более порций овощей в неделю по сравнению с теми, кто употреблял меньше 9 порций в неделю [24]. Такая же обратная связь $(p=0,021)$ была установлена и с высоким количеством ПВ (25 г и более в день в сравнении с 9 г и менее) в рационе питания. Что касается фруктов, то разницы в риске рака поджелудочной железы не было между группой с минимальным (8 порций в неделю) их потреблением и максимальным (33,5 порций в неделю). Однако следует отметить, что в группах со средним потреблением фруктов (14,5 и 21,5 порций в неделю) заболеваемость раком была меньше, чем в группах с минимальным и максимальным потреблением.

В материалах ВФИР 2007 года [1] вероятное снижение риска рака полости рта, глотки и гортани оказывали некрахмалистые овощи (несоленые и немаринованные), фрукты и продукты, содержащие каротиноиды. Все витамины и ПВ фруктов и овощей вошли в группу недостаточно научно обоснованных.

Итальянским медикам удалось показать достоверную обратную связь потребления ПВ и риска развития карциномы носоглотки [25], который снижался на 42 \% в группе с максимальным потреблением ПВ. Также достоверная обратная связь была ими установлена и с потреблением растворимых (пектин) и нерастворимых (клетчатка и лигнин) ПВ. Однако при оценке раздельного вклада ПВ овощей, зерновых или фруктов в снижение риска развития рака носоглотки только последние достоверно $(p=0,03)$ его уменьшали. В отношении ПВ овощей отмечена лишь тенденция к снижению риска $(p=0,09)$, а ПВ зерновых благоприятного влияния не оказали.

Польские исследовательницы [26] приводят данные об использовании геля с включением порошка, полученного из лиофильно высушенной ежевикообразной малины, у пациентов с начальной стадией рака ротовой полости. Назначение его 
4 раза в день в течение 6 недель уменьшало площадь неопластического поражения и предупреждало переход в чешуйчато-клеточный рак полости рта.

В аналитическом обзоре экспертов ВФИР 2007 года [1] вероятный защитный эффект перед угрозой возникновения рака пищевода был доказан для некрахмалистых овощей, фруктов, продуктов, содержащих каротин и продуктов с витамином С. Продукты, содержащие ПВ, фолат и витамин Е, находились на данном этапе развития медицинской науки в разряде предполагаемых в плане снижения риска этого рака.

В исследовании случай - контроль американские ученые сравнили потребление фруктов и овощей здоровыми и больными с впервые диагностированным пищеводом (синдромом) Баррета (предраковое заболевание и одно из факторов риска аденокарциномы пищевода) [27]. Они установили, что ежедневное потребление овощей в количестве не менее 2,5 порций (порция равна 125-150 г) на 2000 ккал рациона питания, а также не менее 4,6 порций овощей вместе с фруктами на 2000 ккал приводит к наибольшему снижению риска развития синдрома Баррета. Другая группа ученых из США [28] доказала, что увеличение содержания ПВ в рационе питания именно за счет фруктов и овощей предупреждает риск развития синдрома Баррета; ПВ зерновых и бобовых такого влияния не оказывали.

Значимость фруктов и овощей в профилактике риска развития основных видов рака пищевода подтверждена еще одной группой ученых США в исследовании случай - контроль, проведенном в трех американских штатах [29], причем с высокой степенью статистической достоверности $(p<0,001)$. Аналогичные данные получены и казахскими учеными [30].

Использование витаминов C ( $\geq 250$ мг) и Е ( $\geq 180$ мг), а также поливитаминов (витамины C, Е, бета-каротин, селен и др.) в рационе питания больных синдромом Баррета (339 человек) способствовало достоверному снижению у них риска развития аденокарциномы пищевода и маркеров прогрессирования неопластических процессов за период наблюдения около 10 лет [31]. Авторы объясняют это противовоспалительным и антиоксидантным действием указанных соединений, нейтрализующих воспаление и окислительное повреждение клеток слизистой оболочки пищевода, вызываемые забросом кислоты и желчи, а также курением.

В Шанхайском когортном исследовании [32] выявлена выраженная статистически достоверная обратная связь между риском развития рака пищевода и употреблением свежих фруктов $(p<0,0001)$, в особенности апельсинов и мандаринов.

Диета, бедная фруктами и овощами, является одним из модифицируемых факторов риска возникновения рака верхних дыхательных и пищеварительных путей - полости рта, гортани, глотки, пищевода [33]. Особо авторы выделяют важность регулярного потребления достаточного количества желтых и оранжевых фруктов, а также зеленых крестоцветных овощей для профилактики указанных онкологических заболеваний.

Иранские медики установили защитное действие высокого потребления фруктов $(p=0,001)[34]$ от рака пищевода, причем статистически достоверным было только влияние бананов, киви и апельсинов ( $p=0,03 ; 0,02$ и 0,01 соответственно). В отношении овощей отмечена лишь небольшая тенденция к снижению риска рака пищевода, наиболее выраженная у темно-зеленых овощей $(p=0,09)$. 
Исследователи из Испании [35] установили, что высокое потребление флавоноидов, в особенности флавонолов, снижает риск развития рака пищевода у курильщиков (у некурящих такой связи не выявлено).

Риск возникновения рака пищевода среди населения одного из южных районов Китая с высоким уровнем этого типа рака существенно (на 45 \%) снижался при увеличении потребления фруктов [36]. Напротив, рост потребления соленых (маринованных) овощей более чем в 2,5 раза повышал риск развития рака пищевода.

По мнению экспертов ВФИР (2007 г.) [1], как некрахмалистые овощи и фрукты, так и, особенно, луковые овощи с большой долей вероятности защищали от рака желудка. Негативное действие отмечено для овощей и фруктов, консервированных с солью и маринованных. Предполагаемое защитное влияние на желудок оказывали продукты, богатые селеном. Что касается ПВ, витамина С, каротиноидов, фруктовых соков с сахаром, то они были отнесены в группу нутриентов и продуктов с недостаточностью научных данных об их воздействии на риск развития рака желудка.

Анализ результатов 19 исследований (в основном случай - контроль) показал отсутствие надежных доказательств влияния чеснока на снижение риска возникновения рака желудка [37]. Однако позже итальянские ученые [38] на основании анализа большого числа исследований делают вывод о том, что, несмотря на отсутствие достоверной связи между риском развития рака желудка и луковыми овощами в большинстве когортных исследований, которые во многом связаны со сложностью установления эффективно действующей дозы, способов кулинарной обработки луковых овощей и т. п., можно предположить их благоприятное влияние при регулярном употреблении, исходя из этиологии рака желудка. Это предположение, по мнению авторов, подтверждается антимикробным действием экстракта, в частности, чеснока на инфекцию Н. Pylori, являющуюся одним из причинных факторов рака желудка.

Австралийские ученые [39] на основании метаанализа большого числа исследований также сделали вывод о наличии у чеснока защитного влияния на желудок и рекомендуют его ежедневное использование в качестве дешевого, доступного и вкусного профилактического средства. Одновременно они отмечают дозозависимый эффект - высокое потребление чеснока (более 3 раз в неделю или более 1,5 кг в год) повышало степень защиты от рака.

Отмечено снижение риска развития рака желудка среди населения Кореи при высоком потреблении зеленого лука на $63 \%$, чеснока и репчатого лука - на $46 \%$, фруктов - на $39 \%$ и грибов - на $57 \%$ по сравнению с группами, где потребление этих продуктов было минимальным [40]. Повышению риска способствовали овощи с высоким содержанием поваренной соли, увеличивавшие риск развития рака желудка в 2 раза. Частое использование листовых овощей достоверно $(p=0,0084)$ снижало риск развития этого заболевания среди населения Тайваня [41].

Здоровое питание с большим количеством овощей и фруктов, богатых антиоксидантами (витамины С и Е, каротиноиды и др.) существенно снижало риск возникновения рака желудка среди населения Китая [42]. Авторы объясняют это способностью витаминов С и Е блокировать образование в желудке нитрозоаминов, обладающих выраженным канцерогенным действием. Одновременно витамин Е защищает полиненасыщенные жирные кислоты клеток желудка от окислительного 
повреждения, способного провоцировать канцерогенез. В свою очередь, ПВ овощей и фруктов, особенно водорастворимые, способны чисто механически очищать поверхность слизистой оболочки желудка, выводя канцерогены через желудочнокишечный тракт. Одновременно ПВ замедляют всасывание крахмала, что уменьшает глюкозную нагрузку и гиперинсулинемию, которая может повышать риск развития рака желудка.

На способность витамина С защищать слизистые оболочки, в том числе желудка, а также тормозить образование нитрозоаминов указывают и авторы из Европы, проанализировавшие в рамках ЕРIC взаимосвязь уровня витамина С в плазме крови с риском возникновения рака желудка [43].

Иранские ученые на основании метаанализа исследований случай - контроль [44] выявили, что высокое потребление фруктов и некрахмалистых овощей снижает риск развития рака желудка на $38 \%$.

Несмотря на малое число исследований, посвященных влиянию овощей и фруктов на риск развития рака печени и желчного пузыря, почек и мочевого пузыря, некоторые выводы все-таки сделать можно. Так, например, хотя в материалах экспертов ВФИР 2015 года [45] фрукты, некрахмалистые овощи и содержащие витамин С продукты отнесены к недостаточно научно обоснованным в снижении риска развития рака печени, китайские исследователи [46] указывают на потенциальную способность снижать риск рака печени у некоторых фруктов, ягод и овощей и их активных соединений: винограда, черной смородины, сливы, граната (флавоноиды, дубильные вещества, проантоцианидины); крестоцветных овощей (изотиоцианаты); помидоров (ликопин и томатин); чеснока (сераорганические соединения). В отношении снижения риска возникновения рака желчного пузыря экспертами ВФИР [47] к разряду недостаточно научно обоснованных отнесены только перцыкапсикумы и продукты, содержащие витамин С.

Влияние фруктов и овощей на риск развития рака почек оценено экспертами ВФИР [48] как недостаточно научно обоснованное, хотя в отдельных исследованиях были выявлены достоверные защитные свойства томатов и крестоцветных овощей от почечно-клеточной карциномы $[49,50]$.

В отношении возникновения рака мочевого пузыря экспертами ВФИР в 2015 году [51] выявлено предполагаемое снижение его риска при сочетании достаточного количества фруктов и овощей в рационе питания. В исследованиях, опубликованных на год позже, установлено, что высокий уровень потребления фруктов способствовал снижению риска на $23 \%$, овощей - на $17 \%$, отдельно цитрусовых - на $15 \%$, отдельно крестоцветных овощей - на 16\% [52]. Кроме того, существенное защитное влияние оказывало высокое содержание в рационе витаминов С, А, Е и фолата, а также селена, снижавших риск этого типа рака на 10, 18, 18, 16 и 39\% соответственно. Однако применение комплексных БАДов с антиоксидантами (витамины C, Е, селен и др.), наоборот, резко повышало риск развития рака мочевого пузыря на $52 \%$.

Выше, при рассмотрении большинства типов злокачественных опухолей, мы указывали на важность фруктово-овощного компонента в рамках здорового питания. В настоящее время растет число людей и в России, и за рубежом, подразумевающих под «здоровым» вегетарианское, а часто и веганское питание. Последнее, видимо, послужило толчком к исследованию английскими учеными влияния раз- 
ных типов питания на заболеваемость и смертность, в том числе от рака [53; 54]. В результате они пришли к довольно неожиданным выводам:

1) заболеваемость раком, как общая, так и отдельными его типами, была самой низкой у рыбоедов, которые ели все, кроме мяса;

2) риск РЛ и колоректального рака (КРР) у вегетарианцев был выше, и в ряде случаев существенно выше, чем у рыбоедов и мясоедов;

3) общая смертность от рака среди вегетарианцев была на $9 \%$ ниже, чем у мясоедов, а у веганов на $14 \%$ выше. При этом смертность от инсультов у веганов также была достоверно выше (на $63 \%)$, чем у мясоедов $(p=0,023)$.

Вероятными причинами такого неожиданного результата является хорошая сбалансированность питания мясоедов, которые употребляли небольшое количество мяса (в среднем 78,1 г в день мужчины и 69,7 г в день женщины) и всего на $20 \%$ меньше фруктов и овощей, чем вегетарианцы. Что касается ситуации среди веганов, то более высокая смертность у них может быть связана с потреблением больших количеств рафинированных углеводных, в том числе фруктовых, овощных и зерновых продуктов питания для обеспечения достаточной энергоценности рациона.

Основным принципам здорового питания максимально соответствует средиземноморская диета. Исследователи из Германии и Австрии [55], проанализировав научную литературу по влиянию средиземноморского типа питания на заболеваемость раком, пришли к однозначному выводу о том, что строгое следование такому питанию приводит к снижению общей смертности от рака и риска развития отдельных типов рака (КРР, дыхательного и пищеварительного тракта, рака молочной железы, желудка, печени, поджелудочной железы, РПЖ, головы и шеи). Для средиземноморского типа питания характерно высокое потребление свежих овощей и фруктов, цельнозерновых продуктов, оливкового масла и рыбы, низкое крахмалистых овощей, мясопродуктов промышленной переработки.

\section{Заключение}

Анализ современной информации по влиянию плодов и овощей на риск развития рака свидетельствует о недостаточном исследовании проблемы. Это выражается в противоречивости данных разных исследователей, иногда приходящих к совершенно противоположным выводам. Данный факт связан с использованием различных методик проведения наблюдений, группировки данных и их оценки. Однако уже на настоящем этапе развития доказательной нутрициологии можно выявить довольно четкие закономерности и многократно проверенные тенденции, позволяющие сделать определенные выводы и наметить пути для дальнейшего решения проблемы.

Так, доказано, что влияние фруктов и овощей на риск развития разных типов онкологических заболеваний отличается, иногда существенно, особенно среди жителей различных регионов земного шара. Кроме того, разные фрукты и овощи по-разному воздействуют на риск развития онкологических заболеваний и смертность от них.

Наиболее выраженные профилактические свойства установлены у яблок и цитрусовых, темных сортов винограда, черники, черной смородины, малины (осо- 
бенно ежевикообразной), овощей, содержащих каротиноиды (томаты, морковь, тыква и др.), а также луковых, крестоцветных и листовых овощей. При этом одним из наиболее эффективных противораковых компонентов являются ПВ в составе продуктов питания, которые способствуют достоверному снижению риска раком молочной железы, КРР, рака поджелудочной железы, пищевода, желудка, а также профилактике рецидивов и увеличению продолжительности жизни больных рака молочной железы. Причем ПВ разных продуктов оказывают неодинаковое защитное действие на онкологическую заболеваемость, т. е. для предупреждения различных раковых заболеваний необходимы ПВ разных продуктов питания. Пищевые волокна в составе БАДов противоракового действия не оказывали, а иногда повышали риск тех или иных онкологических заболеваний.

Кроме того, противораковое действие установлено для многих фитонутриентов, входящих в состав разных овощей и плодов - антиоксидантов (витамины С, Е, селен и др.), каротиноидов (ликопин, альфа- и бета-каротин, зеаксантин и др.), фолатов, флавоноидов, изотиоцианатов, ресвератрола, аллицина и диалилсульфида, но не для БАДов, содержащих указанные соединения.

Сегодня доказана опасность избыточного потребления таких нутриентов, как селен, альфа-токоферол и омега-3 жирные кислоты, которые, в частности, повышали риск развития РПЖ, каротиноиды - риск РЛ, а комплексные БАДы с антиоксидантами (витамины С, Е, селен и др.) - рака мочевого пузыря. Кроме того, установлено увеличение риска возникновения рака поджелудочной железы при избытке в питании фруктов и овощей, богатых фруктозой.

Противораковое действие фруктов и овощей зависит от способов их кулинарной обработки: наиболее полезны свежие фрукты и сырые овощи (в том числе мороженые). Овощи с каротиноидами более полезны в отварном, тушеном виде. Овощи, консервированные солением и маринованием, а также жареные повышают риск развития некоторых типов рака, в основном органов пищеварения.

Для снижения риска онкологических заболеваний важным является не столько использование отдельных групп фруктов и овощей, оказавших наиболее выраженное профилактическое действие на отдельные типы рака, сколько общая противораковая направленность всего рациона питания, аналогичная средиземноморской диете и/или принципам здорового питания, принятым в основных странах мира. При этом доказано, что питание должно иметь противораковую направленность как минимум с подросткового возраста, а лучше - с раннего детского.

Учитывая различные причины возникновения и разные механизмы развития отдельных форм и локализаций злокачественных опухолей, необходим максимально дифференцированный подход в оценке как отдельных продуктов, так и не только отдельных локализаций рака, но и их разновидностей внутри каждой локализации, в том числе учет гистологического типа опухолей, а также генетических различий. Кроме того, важно проведение исследований с качественным дизайном на больших контингентах с исключением систематических и случайных ошибок, а также с учетом в первую очередь клинически значимых исходов (смертность и продолжительность жизни здоровых, качество жизни, скорость метастазирования, ангиогенеза и пролиферации опухоли у больных и т.п.), а не только благоприятной динамики лабораторных показателей. 
Результаты большинства исследований свидетельствуют о необходимости достаточного потребления овощей и плодов для профилактики развития рака практически всех локализаций. Именно достаточного - избыток же может быть опасен, примером чему является чрезмерное потребление фруктов и ягод, богатых фруктозой, повышающее риск рака поджелудочной железы, картофеля - риск почечноклеточной карциномы, а также меньший риск некоторых онкологических заболеваний при среднем потреблении овощей и плодов по сравнению с максимальным и минимальным их количеством в питании.

Сколько же и каких овощей и фруктов надо съедать в день, чтобы снизить риск развития онкологических заболеваний? Рекомендуемые уровни потребления овощей колеблются, по данным разных авторов, от 240 до 402 г в день, фруктов - от 160 до 460 г в день, пищевых волокон - от 25 г в день. Недостатком существующих норм потребления является отсутствие норм для отдельных групп фруктов, ягод и овощей.

\section{References}

1. Food, Nutrition, Physical Activity, and the Prevention of Cancer: A Global Perspective. Washington, 2007. 517 p.

2. Diet, Nutrition, Physical Activity, and Prostate Cancer. Washington, 2014. 53 p.

3. Niclis C., Díaz Mdel P., Eynard A. R., Román M. D., La Vecchia C. Dietary Habits and Prostate Cancer Prevention: A Review of Observational Studies by Focusing on South America. Nutr. Cancer, 2012, vol. 64, no. 1, pp. 23-33. doi: 10.1080/01635581.2012.630163.

4. Diallo A., Deschasaux M., Galan P., Hercberg S., Zelek L., Latino-Martel P., Touvier M. Associations between fruit, vegetable and legume intakes and prostate cancer risk: results from the prospective Supplémentation en Vitamines et Minéraux Antioxydants (SU.VI.MAX) cohort. Br. J. Nutr., 2016, vol. 115, no. 9, pp. 1579-1585. doi: 10.1017/S0007114516000520.

5. Mandair D., Rossi R. E., Pericleous M., Whyand T., Caplin M.E. Prostate cancer and the influence of dietary factors and supplements: a systematic review. Nutr. Metabol., 2014, no. 11: 30. doi: 10.1186/17437075-11-30.

6. Van Poppel H., Tombal B. Chemoprevention of prostate cancer with nutrients and supplements. Cancer Management and Research, 2011, no.3, pp.91-100. doi: 10.2147/CMR.S18503.

7. Thompson I., Kristal A., Platz E. A. Prevention of Prostate Cancer: Outcomes of Clinical Trials and Future Opportunities. Am. Soc. Clin. Oncol. Educ. Book, 2014, pp. e76-e80. doi: 10.14694/EdBook_ AM. 2014.34.e76.

8. Vance T.M., Su J., Fontham E. T.H., Koo S. I., Chun O. K. Dietary Antioxidants and Prostate Cancer: A Review. Nutr. Cancer, 2013, vol. 65, no. 6, pp.793-801. doi:10.1080/01635581.2013.806672.

9. Graff R.E., Pettersson A., Lis R. T., Ahearn T. U., Markt S. C., Wilson K. M., Rider J. R., Fiorentino M., Finn S., Kenfield S. A., Loda M., Giovannucci E. L., Rosner B., Mucci L. A. Dietary lycopene intake and risk of prostate cancer defined by ERG protein expression. Am. J. Clin. Nutr., 2016, vol. 103, no. 3, pp. 851-860. doi: 10.3945/ajcn.115.118703.

10. Key T. J., Appleby P. N., Travis R. C., Albanes D., Alberg A. J., Barricarte A., Black A., Boeing H., Buenode-Mesquita H. B., Chan J.M., Chen C., Cook M. B., Donovan J.L., Galan P., Gilbert R., Giles G. G., Giovannucci E., Goodman G.E., Goodman P.J., Gunter M.J., Hamdy F.C., Heliövaara M., Helzlsouer K. J., Henderson B.E., Hercberg S., Hoffman-Bolton J., Hoover R. N., Johansson M., Khaw K. T., King I. B., Knekt P., Kolonel L. N., Le Marchand L., Männistö S., Martin R. M., Meyer H. E., Mondul A. M., Moy K. A., Neal D. E., Neuhouser M. L., Palli D., Platz E. A., Pouchieu C., Rissanen H., Schenk J.M., Severi G., Stampfer M. J., Tjønneland A., Touvier M., Trichopoulou A., Weinstein S. J., Ziegler R.G., Zhou C.K., Allen N.E. Carotenoids, retinol, tocopherols, and prostate cancer risk: pooled analysis of 15 studies. Am. J.Clin. Nutr., 2015, vol.102, no.5, pp.1142-1157. doi: 10.3945/ ajcn.115.114306.

11. Brasky T.M., Kristal A.R., Navarro S.L., Lampe J.W., Peters U., Patterson R.E., White E. Specialty Supplements and Prostate Cancer Risk in the VITamins and Lifestyle (VITAL) Cohort. Nutr. Cancer, 2011, vol.63, no. 4, pp. 573-582. doi: 10.1080/01635581.2011.553022. 
12. Hardin J., Cheng I., Witte J.S. Impact of consumption of vegetable, fruit, grain, and high glycemic index foods on aggressive prostate cancer risk. Nutr. Cancer, 2011, vol.63, no.6, pp.860-872. doi: 10.1080/01635581.2011.582224.

13. Tantamango-Bartley Y., Knutsen S.F., Knutsen R., Jacobsen B.K., Fan J., Beeson W.L., Sabate J., Hadley D., Jaceldo-Siegl K., Penniecook J., Herring P., Butler T., Bennett H., Fraser G. Are strict vegetarians protected against prostate cancer? Am. J. Clin. Nutr., 2016, vol. 103, no. 1, pp. 153-160. doi: 10.3945/ajcn.114.106450.

14. Adhami V.M., Khan N., Mukhtar H.Cancer Chemoprevention by Pomegranate: Laboratory and Clinical Evidence. Nutr. Cancer, 2009, vol.61, no. 6, pp. 811-815. doi: 10.1080/01635580903285064.

15. Hackshaw-McGeagh L.E., Perry R.E., Leach V.A., Qandil S., Jeffreys M., Martin R.M., Lane J.A. A Systematic Review of Dietary, Nutritional, and Physical Activity Interventions for the Prevention of Prostate Cancer Progression and Mortality. Cancer Causes Control, 2015, vol.26, pp. 1521-1550. doi: 10.1007/s10552-015-0659-4.

16. Stefani E.D., Deneo-Pellegrini H., Boffetta P., Ronco A.L., Aune D., Acosta G., Mendilaharsu M., Brennan P., Ferro G. Dietary Patterns and Risk of Adenocarcinoma of the Lung in Males: A Factor Analysis in Uruguay. Nutr. Cancer, 2011, vol. 63, no. 5, pp. 699-706. doi: 10.1080/01635581.2011.563033.

17. Büchner F. L., Bueno-de-Mesquita H.B., Linseisen J., Boshuizen H.C., Kiemeney L.A., Ros M.M., Overvad K., Hansen L., Tjonneland A., Raaschou-Nielsen O., Clavel-Chapelon F., BoutronRuault M.C., Touillaud M., Kaaks R., Rohrmann S., Boeing H., Nöthlings U., Trichopoulou A., Zylis D., Dilis V., Palli D., Sieri S., Vineis P., Tumino R., Panico S., Peeters P. H., van Gils C. H., Lund E., Gram I. T., Braaten T., Martinez C., Agudo A., Arriola L., Ardanaz E., Navarro C., Rodríguez L., Manjer J., Wirfält E., Hallmans G., Rasmuson T., Key T.J., Roddam A. W., Bingham S., Khaw K.T., Slimani N., Bofetta P., Byrnes G., Norat T., Michaud D., Riboli E. Fruits and Vegetables Consumption and the Risk of Histological Subtypes of Lung Cancer in the European Prospective Investigation into Cancer and Nutrition (EPIC). Cancer Causes Control, 2010, vol.21, pp.357-371. doi: 10.1007/s10552009-9468-y.

18. Takata Y., Xiang Y.-B., Yang G., Li H., Gao J., Cai H., Gao Y.-T., Zheng W., Shu X.-O. Intakes of Fruits, Vegetables, and Related Vitamins and Lung Cancer Risk: Results from the Shanghai Men's Health Study (2002-2009). Nutr. Cancer, 2013, vol. 65, no. 1, pp. 51-61. doi:10.1080/01635581.2013.741757.

19. Gorlova O.Y., Weng Sh.-F., Hernandez L., Spitz M.R., Forman M.R. Dietary Patterns Affect Lung Cancer Risk in Never Smokers. Nutr. Cancer, 2011, vol.63, no.6, pp.842-849. doi: $10.1080 / 01635581.2011 .589958$.

20. Tasevska N., Sinha R., Kipnis V., Subar A.F., Leitzmann M.F., Hollenbeck A.R., Caporaso N.E. Schatzkin A., Cross A.J. A Prospective Study of Meat, Cooking Methods, Meat Mutagens, Heme Iron, and Lung Cancer Risks. Am. J.Clin. Nutr., 2009, vol.89, no.6, pp.1884-1894. doi: 10.3945/ ajcn.2008.27272.

21. World Cancer Research Fund. Washington, 2012. 37 p.

22. Chuang S.-C., Stolzenberg-Solomon R., Ueland P. M., Vollset S. E., Midttun O., Olsen A., Tjonneland A., Overvad K., Boutron-Ruault M.-Ch., Morois S., Clavel-Chapelon F., Teucher B., Kaaks R., Weikert C., Boeing H., Trichopoulou A., Benetou V., Naska A., Jenab M., Slimani N., Romieu I., Michaud D.S., Palli D., Sieri S., Panico S., Sacerdote C., Tumino R., Skeie G., Duell E. J., Rodriguez L., MolinaMontes E., Maria Huerta J., Larranaga N., Barricarte Gurrea A., Johansen D., Manjer J., Ye W., Sund M., Peeters P.H. M., Jeurnink S., Wareham N., Khaw K.-T., Crowe F., Riboli E., Bueno-de-Mesquita B., Vineis P. A U-shaped Association between Plasma Folate and Pancreatic Cancer Risk in the European Prospective Investigation into Cancer and Nutrition. Eur. J.Cancer, 2011, vol.47, no. 12, pp.18081816. doi: 10.1016/j.ejca.2011.02.007.

23. Stolzenberg-Solomon R.Z., Sheffler-Collins S., Weinstein S., Garabrant D. H., Mannisto S., Taylor Ph., Virtamo J., Albanes D. Vitamin E Intake, A-Tocopherol Status, and Pancreatic Cancer in a Cohort of Male Smokers. Am. J. Clin. Nutr., 2009, vol. 89, no. 2, pp. 584-591. doi: 10.3945/ajcn.2008.26423.

24. Zhang J., Dhakal I. B., Gross M. D., Lang N. P., Kadlubar F. F., Harnack L. J., Anderson K. E. Physical Activity, Diet, and Pancreatic Cancer: A Population-Based Case-Control Study in Minnesota. Nutr. Cancer, 2009, vol. 61, no. 4, pp. 457-465. doi: 10.1080/01635580902718941.

25. Bidoli E., Pelucchi C., Polesel J., Negri E., Barzan L., Franchin G., Franceschi S., Serraino D., De Paoli D., La Vecchia D., Talamini R. Fiber Intake and Risk of Nasopharyngeal Carcinoma: A CaseControl Study. Nutr. Cancer, 2013, vol. 65, no. 8, pp. 1157-1163. doi: 10.1080/01635581.2013.828088.

26. Kula M., Krauze-Baranowska M. Rubus Occidentalis: The Black Raspberry - its Potential in the Prevention of Cancer. Nutr. Cancer, 2016, vol. 68, no. 1, pp. 18-28. doi: 10.1080/01635581.2016.1115095. 
27. Thompson O.M., Beresford S.A.A., Kirk E. A., Vaughan T.L. Vegetable and Fruit Intakes and Risk of Barrett's Esophagus in Men and Women. Am. J. Clin. Nutr., 2009, vol. 89, no.3, pp.890-896. doi: 10.3945/ajen.2008.26497.

28. Kubo A., Block G., Quesenberry C.P. Jr., Buffler P., Corley D. A. Effects of Dietary Fiber, Fats, and Meat Intakes on the Risk of Barrett's Esophagus. Nutr. Cancer, 2009, vol.61, no. 5, pp.607-616. doi: $10.1080 / 01635580902846585$.

29. Navarro Silvera S. A., Mayne S. T., Risch H.A., Gammon M. D., Vaughan T., Chow W.H., Dubin J. A., Dubrow R., Schoenberg J., Stanford J.L., West A. B., Rotterdam H., Blot W. J. Principal Component Analysis of Dietary and Lifestyle Patterns in Relation to Risk of Subtypes of Esophageal and Gastric Cancer. Ann. Epidemiol., 2011, vol.21, no. 7, pp. 543-550. doi: 10.1016/j.annepidem.2010.11.019.

30. Orazova G. U., Karp L.L., Dossakhanov A.Kh., Sauyekenova L.N., Zhaksalykova G. B., Bukhanovskaya L.V., Zhylkaydarova A.Zh., Zhapparov E.I. Nekotorye osobennosti obraza zhizni kak prediktory zlokachestvennykh novoobrazovanii verkhnikh otdelov zheludochno-kishechnogo trakta [Some aspects of lifestyle as predictors of malignant neoplasms of upper gastrointestinal tract]. J. Clin. Med. Kaz., 2015, vol.1, no. 35, pp. 45-50. (In Russian)

31. Dong L.M., Kristal A.R., Peters U., Schenk J.M. Dietary Supplement Use and Risk of Neoplastic Progression in Esophageal Adenocarcinoma: A Prospective Study. Nutr. Cancer, 2008, vol.60, no. 1, pp. 39-48. doi: 10.1080/01635580701586762.

32. Fan Y., Yuan J.-M., Wang R. Gao Y.-T., Yu M.C. Alcohol, Tobacco and Diet in Relation to Esophageal Cancer: The Shanghai Cohort Study. Nutr. Cancer, 2008, vol.60, no.3, pp.354-363. doi: $10.1080 / 01635580701883011$.

33. Gupta B., Johnson N.W. Emerging and Established Global Life-Style Risk Factors for Cancer of the Upper Aero-Digestive Tract. Asian Pac. J. Cancer Prev., 2014, vol. 15, no. 15, pp. 5983-5991. doi: 10.7314/APJCP. 2014.15.15.5983.

34. Hajizadeh B., Jessri M., Moasheri S. M., Rad A. H., Rashidkhani B. Fruits and Vegetables Consumption and Esophageal Squamous Cell Carcinoma: A Case-Control Study. Nutr. Cancer, 2011, vol.63, no. 5, pp. 707-713. doi: 10.1080/01635581.2011.563028.

35. Vermeulen E., Zamora-Ros R., Duell E. J., Luján-Barroso L., Boeing H., Aleksandrova K., Bueno-deMesquita H. B., Scalbert A., Romieu I., Fedirko V., Touillaud M., Fagherazzi G., Perquier F., MolinaMontes E., Chirlaque M.D., Vicente Argüelles M., Amiano P., Barricarte A., Pala V., Mattiello A., Saieva C., Tumino R., Ricceri F., Trichopoulou A., Vasilopoulou E., Ziara G., Crowe F. L., Khaw K. T., Wareham N.J., Lukanova A., Grote V.A., Tjønneland A., Halkjær J., Bredsdorff L., Overvad K., Siersema P. D., Peeters P. H., May A. M., Weiderpass E., Skeie G., Hjartåker A., Landberg R., Johansson I., Sonestedt E., Ericson U., Riboli E., González C. A. Dietary Flavonoid Intake and Esophageal Cancer Risk in the European Prospective Investigation into Cancer and Nutrition Cohort. Am. J. Epidemiol., 2013, vol. 178, no. 4, pp. 570-581. doi: 10.1093/aje/kwt026.

36. Tan H.Z., Lin W. J.,Huang J. Q., Dai M., Fu J.H., Huang Q.H., Chen W. M., Xu Y.L., Ye T.T., Lin Z.Y., Lin X.S., Cai J.X., Dong Y.H., Luo H.Y., Chen S.H., Huang Y.L., Yang J., Lin A.X., Yuan X.Q., Chen S. Y., Wang K. S., Zhuang C. Y., Wang S. C., Lin L. L., Zou X. F., Song Z. H., Fang X. H., Chen T., Zhang J.H., Li K. Q., Chen L. H., Lin X. P., Lin J. M., Lin J. N., Lin P. L., Chen J. T., Lin K. M., Hong X. C., Wang L. D., Xu L. Y., Li E. M., Zhang J.J. Updated incidence rates and risk factors of esophageal cancer in Nan'ao Island, a coastal high-risk area in southern China. Dis. Esophagus, 2017, vol.30, no. 1, pp. 1-7. doi: 10.1111/dote.12468.

37. Kim J. Y., Kwon O. Garlic Intake and Cancer Risk: an Analysis Using the Food and Drug Administration's Evidence-Based Review System for the Scientific Evaluation of Health Claims. Am. J. Clin. Nutr., 2009, vol. 89, no. 1, pp. 257-264. doi: 10.3945/ajcn.2008.26142.

38. Guercio V., Galeone C., Turati F., La Vecchia C. Gastric Cancer and Allium Vegetable Intake: A Critical Review of the Experimental and Epidemiologic Evidence. Nutr. Cancer, 2014, vol.66, no. 5, pp.757773. doi: 10.1080/01635581.2014.904911.

39. Kodali R.T., Eslick G.D. Meta-Analysis: Does Garlic Intake Reduce Risk of Gastric Cancer? Nutr. Cancer, 2015, vol. 67, no. 1, pp. 1-11. doi: 10.1080/01635581.2015.967873.

40. Woo H.D., Park S., Oh K., Kim H. J., Shin H.R., Moon H.K., Kim J. Diet and Cancer Risk in the Korean Population: A Meta-analysis. Asian Pac. J. Cancer Prev., 2014, vol. 15, no. 19, pp. 8509-8519. doi: 10.7314/APJCP. 2014.15.19.8509.

41. Hsiung H., Fann J.C., Yen A.M., Chen S.L.-Sh., Chiu Sh. Y.-H., Ku T.-H., Liu T.-U., Chen H.-H., Lin M.-W. Stage-specific Dietary Factors Associated with the Correa Multistep and Multifactorial Process of Human Gastric Carcinogenesis. Nutr. Cancer, 2016, vol.68, no.4, pp.598-610. doi: $10.1080 / 01635581.2016 .1156712$. 
42. Shu L., Wang X.Q., Wang S.F., Wang S., Mu M., Zhao Y., Sheng J., Tao F.B. Dietary Patterns and Stomach Cancer: A Meta-Analysis. Nutr. Cancer, 2013, vol.65, no.8, pp.1105-1115. doi: 10.1080/01635581.2013.828086.

43. Duell E.J., Lujan-Barroso L., Llivina C., Muñoz X., Jenab M., Boutron-Ruault M.-Ch., ClavelChapelon F., Racine A., Boeing H., Buijsse B., Canzian F., Johnson Th., Dalgård Ch., Overvad K., Tjønneland A., Olsen A., Sánchez, Sánchez-Cantalejo E., Huerta J.-M., Ardanaz E., Dorronsoro M., Khaw K.-T., Travis R. C., Trichopoulou A., Trichopoulos D., Rafnsson S., Palli D., Sacerdote C., Tumino R., Panico S., Grioni S., Bueno-de-Mesquita H. B., Ros M. M., Numans M.E., Peeters P. H., Johansen D., Lindkvist B., Johansson M., Johansson I., Skeie G., Weiderpass E., Duarte-Salles T., Stenling R., Riboli E., Sala N., González C. A. Vitamin C Transporter Gene (SLC23A1 and SLC23A2) Polymorphisms, Plasma Vitamin C Levels, and Gastric Cancer Risk in the EPIC Cohort. Genes Nutr., 2013, no. 8, pp. 549-560. doi: 10.1007/s12263-013-0346-6.

44. Raei N., Behrouz B., Zahri S., Latifi-Navid S. Helicobacter Pylori Infection and Dietary Factors Act Synergistically to Promote Gastric Cancer. Asian Pac. J. Cancer Prev., 2016, vol. 17, no. 3, pp.917-921. doi: 10.7314/APJCP. 2016.17.3.917.

45. World Cancer Research Fund International. Washington, 2015. 52 p.

46. Zhou Y., Li Y., Zhou T., Zheng J., Li S., Li H. B. Dietary Natural Products for Prevention and Treatment of Liver Cancer. Nutrients, 2016, vol. 8, no. 36: 156. doi:10.3390/nu8030156.

47. Diet, Nutrition, Physical Activity and Gallbladder Cancer. Washington, 2015. 28 p.

48. Diet, Nutrition, Physical Activity and Kidney Cancer. Washington, 2015. 48 p.

49. Liu B., Mao Q., Wang X., Zhou F., Luo J., Wang C., Lin Y., Zheng X., Xie L. Cruciferous Vegetables Consumption and Risk of Renal Cell Carcinoma: A Meta-Analysis. Nutrition and Cancer, 2013, vol.65, no. 5, pp. 668-676. DOI: 10.1080/01635581.2013.795980.

50. Grieb S. M., Theis R. P., Burr D., Benardot D., Siddiqui T., Asal N. R. Food Groups and Renal Cell Carcinoma: Results from a Case-Control Study. J. Am. Diet. Assoc., 2009, vol. 109, no. 4, pp. 656-667. doi: 10.1016/j.jada.2008.12.020.

51. Diet, Nutrition, Physical Activity and Bladder Cancer. Washington,2015. 36 p.

52. Al-Zalabani A. H., Stewart K. F. J., Wesselius A., Schols A. M. W. J., Zeegers M. P. Modifiable risk factors for the prevention of bladder cancer: a systematic review of meta-analyses. Eur. J. Epidemiol., 2016, vol.31, no. 9, pp. 811-851. doi: 10.1007/s10654-016-0138-6.

53. Key T.J., Appleby P.N., Spencer E. A., Travis R.C., Roddam A.W., Allen N.E. Cancer incidence in vegetarians: results from the European Prospective Investigation into Cancer and Nutrition (EPICOxford). Am. J. Clin. Nutr., 2009, vol. 89 (suppl.), pp.1620S-1626S. doi: 10.3945/ajcn.2009.26736M.

54. Appleby P.N., Crowe F. L., Bradbury K.E., Travis R. C., Key T. J. Mortality in vegetarians and comparable nonvegetarians in the United Kingdom. Am. J. Clin. Nutr., 2016, vol. 103, no. 1, pp. 218-230. doi: 10.3945/ajcn.115.119461.

55. Schwingshackl L., Hoffmann G. Does a Mediterranean-Type Diet Reduce Cancer Risk? Curr. Nutr. Rep., 2016, no. 5, pp.9-17. doi: 10.1007/s13668-015-0141-7.

Статья поступила в редакцию 19 июня 2017 г. Статья принята в печать 22 октября 2017 г.

Контактная информация:

Закревский Виктор Вениаминович — д-р мед. наук; Viktor.Zakrevskii@szgmu.ru Лифляндский Владислав Геннадьевич - д-р мед. наук, проф.; vladlif@mail.ru

\section{Vegetables and fruits in the prevention and treatment of cancer in the light of evidence-based medicine (part 2)}

\section{V.Zakrevskii, V. G. Liflyandsky}

North-West State Medical University named after I. I. Mechnikov, 41, ul. Kirochnaya, St.-Petersburg, 191015, Russian Federation 
For citation: Zakrevskii V. V., Liflyandsky V.G. Vegetables and fruits in the prevention and treatment of cancer in the light of evidence-based medicine (part 2). Vestnik of Saint Petersburg University. Medicine, 2018, vol.13, issue 1, pp.91-105. https://doi.org/10.21638/11701/spbu11.2018.109

A survey of existing literature has analyzed the effect of vegetables and fruits on the risk of developing cancer of the prostate, lungs, pancreas, oral cavity, pharynx and larynx, esophagus and stomach, liver and gallbladder, kidneys and urinary bladder and justifies the possibility of their use for the prevention of these diseases and to improve the quality of life of patients with cancer. It has been established that in order to reduce the risk of cancer, it is not so much the use of certain groups of fruits and vegetables that have the most pronounced preventive effect on certain types of cancer, but rather the overall anti-cancer focus of the entire diet, as well as their sufficient intake. Recommended levels of consumption of vegetables vary according to different authors from 240 to 402 grams per day, fruits - from 160 to 460 grams per day, dietary fiber - from 25 grams per day. The drawback of existing norms of consumption is the lack of norms for certain groups of fruits, berries and vegetables. Given the various causes and different mechanisms of the development of individual forms and localizations of malignant tumors, a maximally differentiated approach is needed in the evaluation of both individual products, individual cancer localizations and their varieties within each localization, including the histological type of tumors and also genetic differences. In addition, it is important to conduct research with qualitative design on large contingents, with the exception of systematic and accidental errors, and also taking into account, in the first place, clinically relevant outcomes (mortality and life expectancy of healthy persons, quality of life, metastasis rate, angiogenesis and tumor proliferation in patients etc.), and not only favorable dynamics of laboratory indicators.

Keywords: vegetables, fruits, berries, prevention and treatment of cancer, evidence-based medicine.

Author's information:

Zakrevskii ViktorV. - MD; Viktor.Zakrevskii@szgmu.ru

Liflyandsky Vladislav G. _ MD, professor; vladlif@mail.ru 